\title{
How can we tap into the Mineral Microbiome?
}

\author{
ROBERT GREENE ${ }^{1}$, DR. W. SCOTT DUNBAR ${ }^{2}$ \\ ${ }^{1}$ Norman B. Keevil Institute of Mining Engineering, \\ University of British Columbia, rgreene4@mail.ubc.ca \\ ${ }^{2}$ Norman B. Keevil Institute of Mining Engineering, \\ University of British Columbia, scott.dunbar@ubc.ca
}

Since the emergence of life a mere 500 million years after the cooling of the Earth's crust, microbes have been interacting with minerals. Fast forward about 2.5 billion years and these interactions have helped to increase the number of mineral species from 1500 to over 5000. The goal of mineral-microbe interactions is to obtain energy by the transfer of electrons between inorganic crystals and living cells. Microbial communities in and near mineral sources are therefore a rich source of genes with instructions for the production of biomolecules evolved to both fabricate and decompose minerals. We suggest this information could be used to create synthetic or modified microbiomes that separate and concentrate metals. The result would be a complete paradigm change with enormous scope for transforming the way metals are obtained and for changing our relationship with minerals and materials. Ideas for how this genetic treasure trove might be exploited are presented. Since microbes fabricate and decompose minerals, it follows that they must have evolved methods to sequester, reduce, and template ions out of solution into crystals, for attaching themselves to crystal faces, and for decomposing crystals back into ions. An enormous number of macromolecules such as proteins and peptides have evolved to attach specifically to particular minerals and metal ions. Direct identification of these large macromolecules is difficult, but techniques are available to identify short sequences of amino acids (peptides) that bind to minerals of economic interest. We show examples of how these peptides can be used to separate particles of minerals of economic interest from waste mineral particles. 